\title{
RESPIRATORY STRIDOR PRODUCED BY AN ABERRANT PULMONARY ARTERY
}

\author{
BY \\ W. H. SCHUTT and P. M. ROBB \\ From the Royal Hospital for Sick Children, Edinburgh
}

(RECEIVED FOR PUBLICATION DECEMBER 10, 1958)

Of recent years increasing interest has been shown in congenital abnormalities of the heart and great vessels because of the possibility of successful surgical correction in certain types of defect. The following case presented as one of congenital stridor in which an anomalous vascular ring was diagnosed clinically and eventually confirmed at autopsy; its exact nature was unsuspected and would have perplexed the operating surgeon. It is for this reason that the case is being published.

\section{Clinical History}

The child, a male infant, was admitted to the hospital aged 1 month.

The pregnancy had been normal and at 36 weeks' gestation the mother was delivered of twins, one of which was quite normal. The other, our patient, was an obvious mongol. His birth weight was $5 \mathrm{lb} .9 \mathrm{oz}$.

While in the maternity hospital the child did well but soon after discharge he developed a slight nasal discharge and some difficulty with feeding.

One week prior to admission he began to have attacks during which he would choke and become blue and very limp. Gentle patting on the back would be followed by recovery. Usually these turns lasted for no longer than a minute and occurred two or three times a day.

On arrival at hospital the diagnosis of mongolism was confirmed. He was also found to have a marked inspiratory stridor with suprasternal and subcostal indrawing. Crying precipitated marked cyanosis. A soft systolic murmur was audible over the precordium but no other abnormality of the cardiovascular or respiratory systems was detected. Routine haematological investigations and a teleradiogram were within normal limits.

The child was placed in an oxygen tent and over the next 48 hours seemed to improve considerably. The stridor persisted, but no further cyanotic attacks occurred until the evening of the third day after admission. These then gradually became more frequent and it was at this stage that a vascular ring constricting the trachea was suspected. No confirmatory radiographic studies were undertaken, however, and the child died on the fifth day in hospital.
Findings at Autopsy. At autopsy it was confirmed that a vascular ring was compressing the trachea.

A persistent left superior vena cava was present, draining into a dilated coronary sinus (see Figs. 1 and 2).

The pulmonary trunk arose normally from the right ventricle. Just before it curved beneath the arch of the aorta, it gave off the ductus arteriosus, which was patent (see Fig. 2). When it reached the right border of the aortic arch, the pulmonary trunk divided into three; the two smaller divisions passed to the upper and lower lobes of the right lung respectively, while the larger division curved sharply to the left, running posterior to the trachea, between it and the oesophagus, to reach the hilum of the left lung (see Fig. 3). The trachea was thus enclosed in a vascular ring composed of the anomalous left pulmonary artery posteriorly and the left upper pulmonary vein anteriorly (Fig. 1). The pressure by the upper left pulmonary vein on the anterior surface of the trachea was reinforced by the arch of the aorta and the left superior vena cava. The lungs showed generalized emphysema.

A moderate quantity of clear fluid was found in the peritoneal cavity. The liver, spleen, and kidneys showed nothing of pathological interest beyond moderate venous congestion.

\section{Discussion}

Vascular rings produced by various anomalies of the aorta and its branches causing compression of the trachea have been recognized and successfully treated for some time, but stridor caused by an anomalous left pulmonary artery seems not to have been recorded until 1954 (Welsh and Munro, 1954). Since then, four further cases have been recorded (Potts, Holinger and Rosenblum, 1954; Morse and Gladding, 1955; Wittenborg, Tantiwongse and Rosenberg, 1956 - two cases). Respiratory obstruction in these cases is usually fairly severe, but there may be slight differences in its manifestation depending on whether the obstruction involves the right main bronchus only or the distal portion of the trachea and consequently whether the child has unilateral or bilateral emphysema. Three infants 

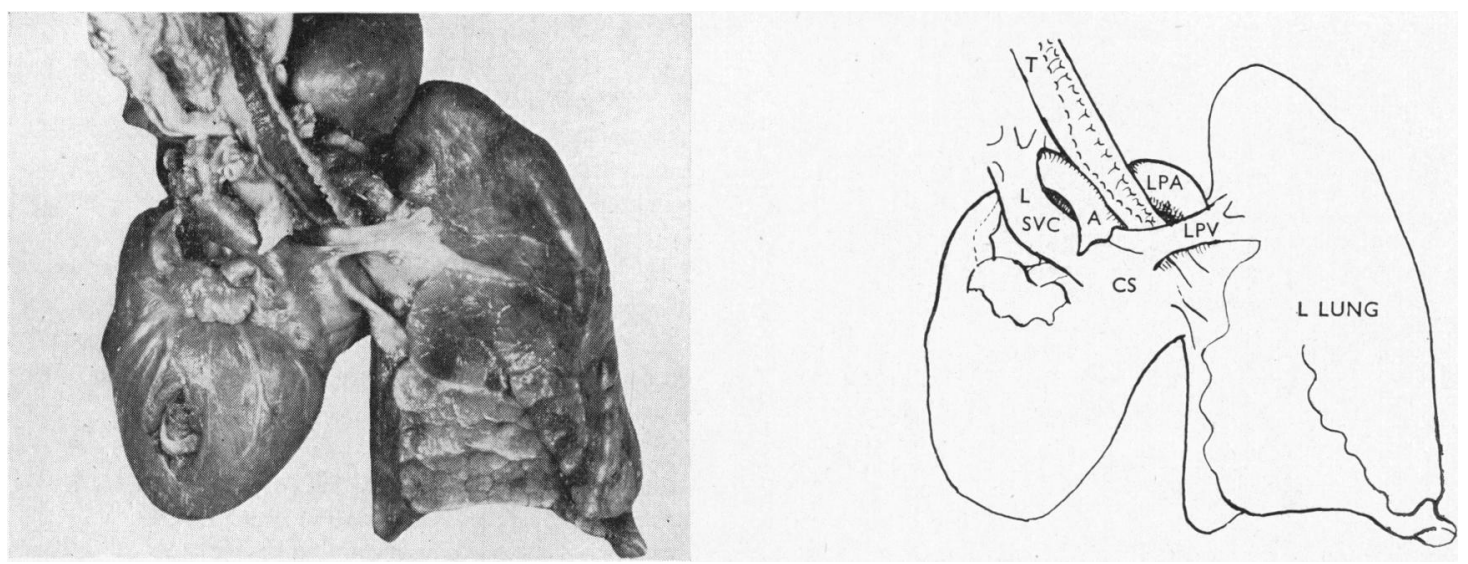

Fig. 1.-Left lung and heart seen from left. Trachea (T.) encircled by left pulmonary artery (L.P.A.) and left pulmonary vein (L.P.V.) reinforced anteriorly by aorta (A.) and left superior vena cava (L.S.V.C.) which drains into coronary sinus (C.S.).
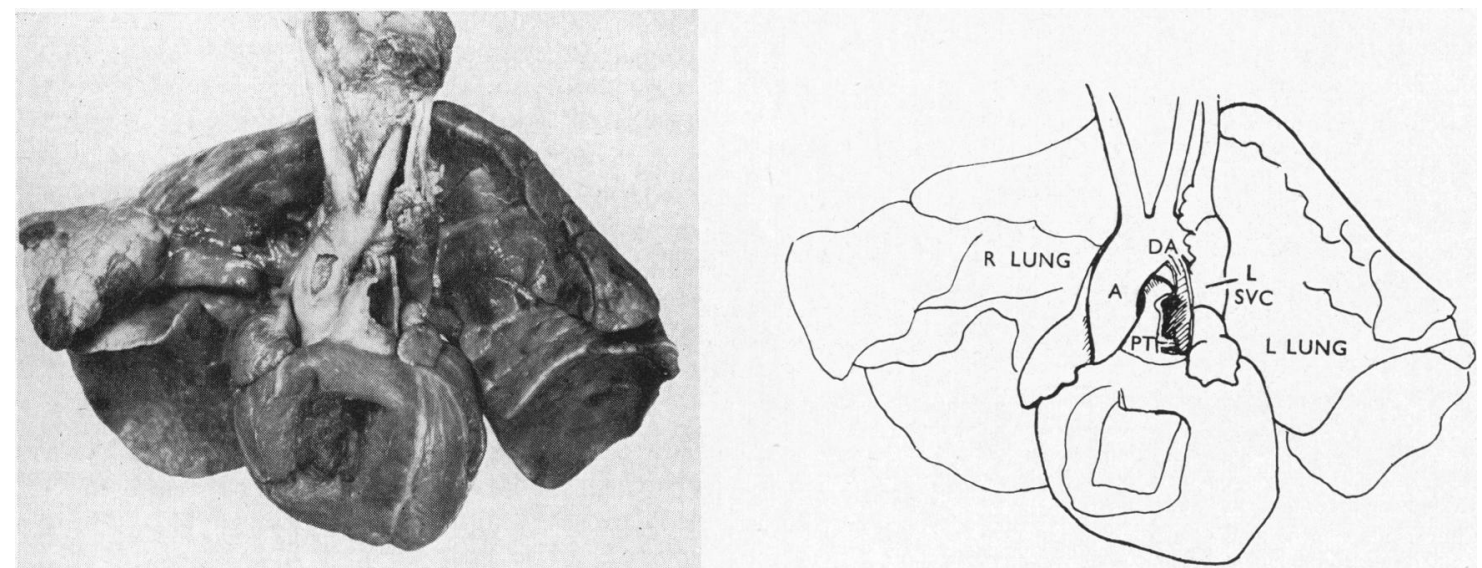

Fig. 2.-Heart and lungs seen from front, showing undivided pulmonary trunk (P.T.) curving beneath aorta after giving off ductus arteriosus (D.A.). A. Aorta.
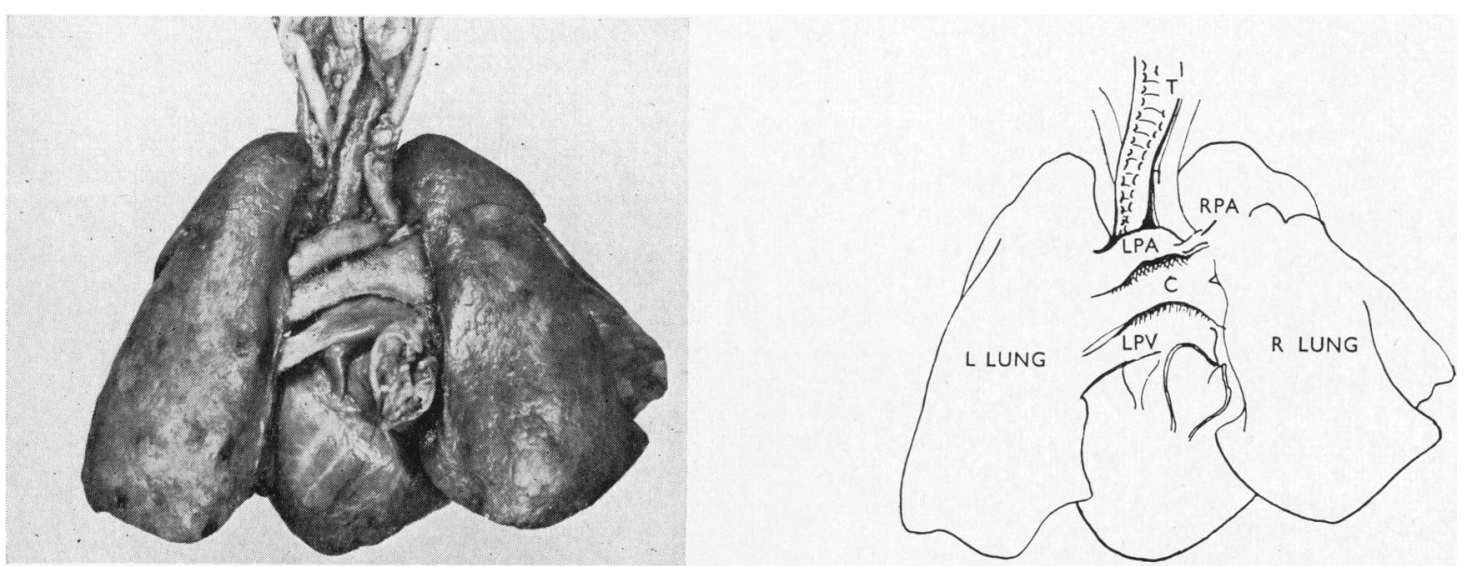

Fig. 3.-Heart and lungs from behind. Aberrant left pulmonary artery (L.P.A.) is seen crossing behind trachea (T.). C. Carina. 


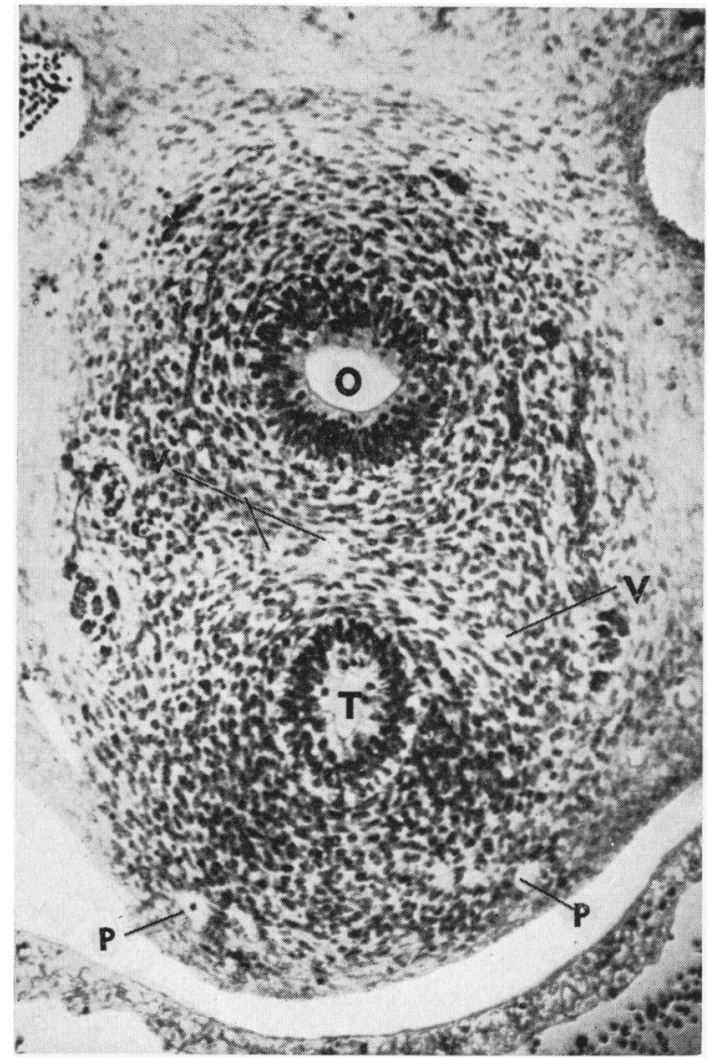

FIG. 4.-A transverse section of the trachea (T.) and oesophagus (O.) from a six-week, $9.0 \mathrm{~mm}$., human embryo. The two pulmonary arteries (P.) are seen ventral to the trachea. Vessels (V.) of the foregut splanchic plexus are present within the mesenchyme which surrounds the trachea and which lies between the trachea and oesophagus. $\times 200$.

with anomalous left pulmonary arteries have been submitted to surgery. One child died of cardiac arrest before any attempt could be made to correct the fault (Welsh and Munro, 1954); one died 11 days after operation (Morse and Gladding, 1955); and one survived and showed dramatic improvement (Potts et al., 1954). In the case of the child who died during the operation the trachea was compressed by the anomalous artery; in the other two cases the right main bronchus was compressed and the method used was division and anterior transplantation of the left pulmonary artery. It is probable that the site of the compression is an important factor in determining whether or not the fault can be successfully corrected. A child with a compressed right main bronchus and one emphysematous lung might stand a better chance than a child with a compressed trachea and bilateral emphysema. Another important factor is the presence or absence of additional anomalies. Of the six patients with aberrant left pulmonary arteries (including ours), two had a persistent left superior vena cava which would add to the surgeon's difficulties (neither of these was operated on), and two were mongols.

Embryological Considerations. According to Jordan and Kindred (1948) rudiments of the pulmonary arteries appear in two places. One branch grows from the base of the sixth arch towards the lung primordium and the other from the mesenchyme surrounding the lung primordium towards the sixth arch. It is conceivable that the downgrowth from the sixth arch might fail to occur on the left side and that the vessels from the left lung primordium would then connect with the developing right pulmonary artery instead of the left. The connexion would take place by way of a channel formed from the vessels of the foregut splanchnic plexus surrounding the trachea and lying between trachea and oesophagus. This can be well visualized on looking at Fig. 4 (Muir, 1958).

\section{Summary}

A case of an aberrant left pulmonary artery producing stridor is described. The literature is briefly reviewed and the treatment of the condition discussed. The embryology is considered.

We would like to express our appreciation to Dr. D. M. Douglas for permission to publish this case and much encouragement. We would also thank Professor R. W. B. Ellis and Dr. A. R. Macgregor for much helpful criticism and advice.

\section{REFERENCES}

Jordan, H. E. and Kindred, J. E. (1948). Textbook of Embryology, Sth ed. D. Appleton-Century Company, London and New

Morse, H. R. and Gladding, S. (1955). Amer. J. Dis. Child., 89, 351. Muir, A. (1958). Personal communication.

Potts, W. J., Holinger, P. H. and Rosenblum, A. H. (1954). J. Amer. med. Ass., 155, 1409.

Welsh, T. M. and Munro, I. B. (1954). Arch. Dis. Childh., 29, 101.

Wittenborg, M. H., Tantiwongse, T. and Rosenberg, B. F. (1956). Radiology, 67, 339. 